Proceedings of the $29^{\text {th }}$ International Conference on Coastal Engineering 19-24 ${ }^{\text {th }}$ September 2004 Lisbon, Portugal

\title{
MARINE ECOSYSTEM ENHANCEMENT ON A GEOTEXTILE COASTAL PROTECTION REEF - NARROWNECK REEF CASE STUDY -
}

\author{
LESLIE (ANGUS) JACKSON \\ International Coastal Management, PO Box 7196 GCMC \\ Gold Coast, Queensland, Australia 9726 \\ RUSSELL E. REICHELT \\ CRC Reef Research Centre, PO Box 772 \\ Townsville, Queensland, Australia 4810 \\ SIMON RESTALL \\ Soil Filters Australia, PO Box 727 GCMC \\ Gold Coast, Queensland, Australia 9726 \\ BOBBIE CORBETT \\ International Coastal Management, PO Box 7196 GCMC \\ Gold Coast, Queensland, Australia 9726 \\ RODGER TOMLINSON \\ Griffith Centre for Coastal Management, Griffith University, PO Box 50 GCMC \\ Gold Coast, Queensland, Australia 9726 \\ JOHN MCGRATH \\ Gold Coast City Council, PO Box 5042 GCMC \\ Gold Coast, Queensland, Australia 9726
}

The Narrowneck Artificial Reef [Gold Coast, Australia] was constructed in 1999 / 2000 out of large sand-filled geotextile containers. It quickly became evident that the containers provided an excellent substrate for marine flora and the development of a diverse ecosystem. As a result, the reef has become popular with locals for fishing, diving, snorkeling and spearfishing. In the years since it was constructed, monitoring of the ecological aspects of the reef has been undertaken. While macroalgae and pelagic fish dominate the reef, it is also home to a wide variety of benthos, fish and other marine fauna. Influenced by the East Australia Current and wave action from the Pacific Ocean, driven by the South East Trade Winds, the reef exhibits a different community structure in comparison to other natural reefs of the Gold Coast. The popularity of the Narrowneck Reef has clearly shown that enhancing the ecological environment and improving recreational amenity have potential benefits on eco-tourism as well as local biodiversity.

1

Jackson, Reichelt, Restall, Corbett, Tomlinson \& McGrath 


\section{Introduction}

An artificial reef was constructed at Narrowneck (Gold Coast, Australia) between August 1999 and December 2000 (Jackson et al. 2002). Narrowneck is an open surf beach on the east coast of Australia, influenced by the East Australia Current and wave action from the Pacific Ocean driven by the South East Trade Winds. Average offshore significant wave height is $1 \mathrm{~m}$ with storm waves up to $\sim 12 \mathrm{~m}$. The coast experiences an average littoral drift northward of some $500,000 \mathrm{~m}^{3} /$ year. Water quality is typically high as there are no major rivers or industrial effluents nearby.

The reef structure is approximately $170 \mathrm{~m}$ long (shore parallel) and $270 \mathrm{~m}$ wide [Photo 1] and is composed of 410 large sand-filled geotextile containers approximately $20 \mathrm{~m}$ in length and varying in capacity between $100 \mathrm{~m}^{3}$ and $300 \mathrm{~m}^{3}$. The reef is constructed on the seaward extent of the surf zone and varies in depth from $-1.5 \mathrm{~m}$ to $-10 \mathrm{~m}$ LAT. As such, the footprint and depth range covered by the reef is substantial, although the entire reef is within the active zone.

The project's primary objective was to protect the nourished beaches, with the secondary objective to improve surfing conditions.

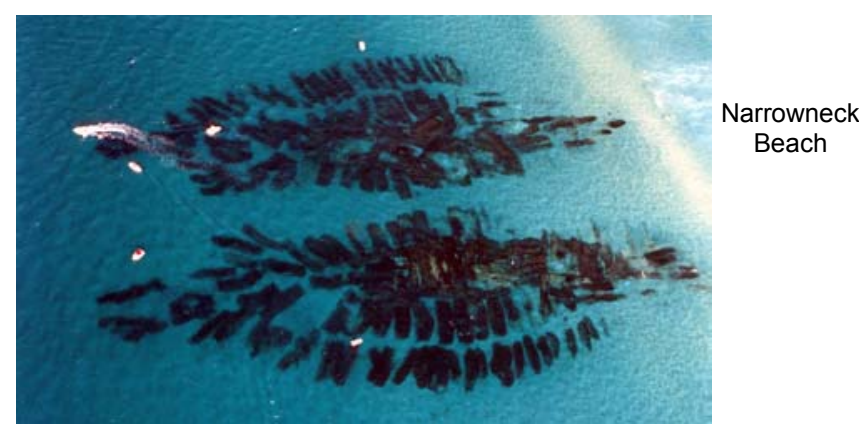

Photo 1: Narrowneck Reef

In the Environmental Impact Assessment, the reef was expected to attract and concentrate fish, but extensive marine flora was not expected to adhere to the geotextile, particularly in shallower areas, owing to wave action. The staplefibre needle-punched composite geotextile, however, has provided a good substratum for a diverse range of marine flora and fauna and the extent and diversity of the habitat created has exceeded expectations considerably.

Jackson, Reichelt, Restall, Corbett, Tomlinson \& McGrath 

19-24 ${ }^{\text {th }}$ September 2004 Lisbon, Portugal

The diversity is far greater than that found on a timber wreck nearby, which is located in a water depth of $-5 \mathrm{~m}$ LAT. The development of this diverse ecosystem has been relatively rapid and contributes to the environmental and recreational value of this reef. The reef now provides a high quality fishing and diving location [Photos 2, $3 \& 4$ ] which has become popular with the locals as well as tourists. As the vegetation is predominately "soft", it does not present a risk to surfers and swimmers. In order to avoid damage to the habitat and structure, the reef has been declared a no anchoring zone.

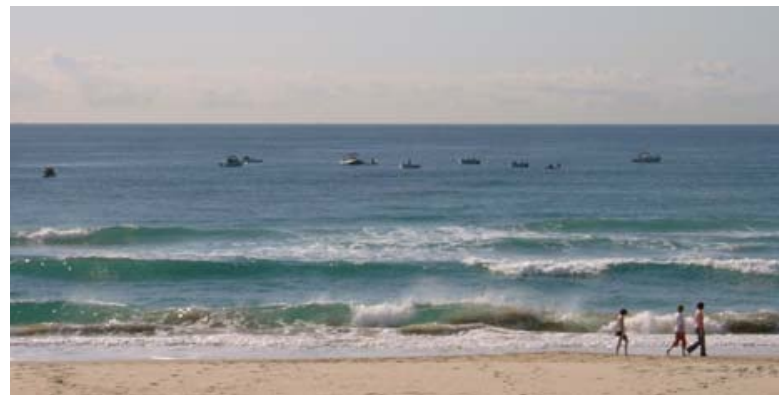

Photo 2: Fishing boats on Narrowneck

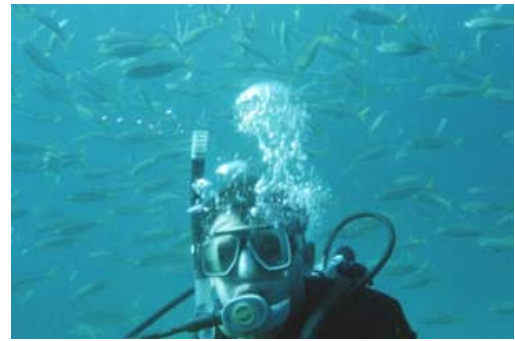

Photo 3: Diver on Narrowneck Reef

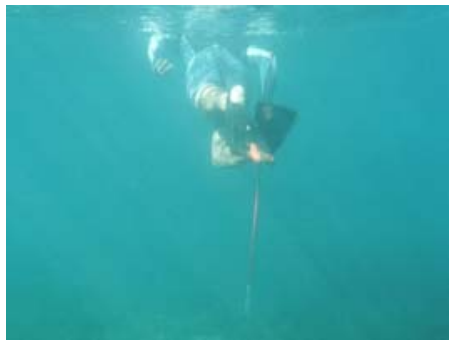

Photo 4: Spearfisherman on Narrowneck Reef

Jackson, Reichelt, Restall, Corbett, Tomlinson \& McGrath 


\section{Monitoring}

19-24 ${ }^{\text {th }}$ September 2004 Lisbon, Portugal

Monitoring was commenced during the construction phase using still and video photography with SCUBA equipment. Continued monitoring over the five years since construction, the development of benthos and the increased diversity of both benthos and nekton has been documented. In 2002, a survey of biological diversity was undertaken by National Marine Science Centre [NMSC] to better quantify the biodiversity achieved at Narrowneck. This involved the comparison of four $25 \mathrm{~m}$ transects taken at Narrowneck with similar results taken from three other similar reefs on the Gold Coast, namely the Palm Beach, Kirra and Cook Island Reefs.

\subsection{Development of Benthos}

Habitat development occurred more rapidly than anticipated. Within days, small pieces of drifting weed are caught within the fibres of the geotextile fabric. Within a week, a light film of algae is evident on the containers [Photo $5]$, with $\sim 50 \mathrm{~mm}$ of algae completely covering the container after $2-3$ weeks [Photo 6]. Growth of marine flora at this point is dependent on the container material and water depth. At Narrowneck, this involved the growth of predominantly shorter types of algae in the shallower areas [Photo 7] that are strongly affected by wave action, and longer types of algae growing densely in the mid-depths [Photo 8] with kelps in the deeper, less energetic areas [Photo 9].

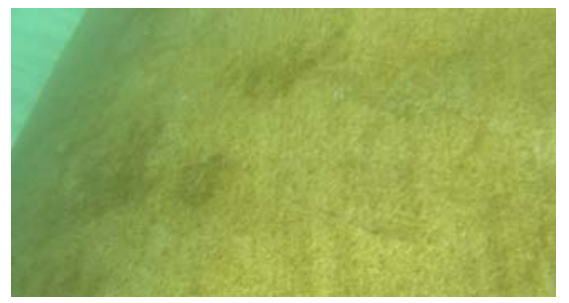

Photo 5: Light film of algae on container [8 days after placement]

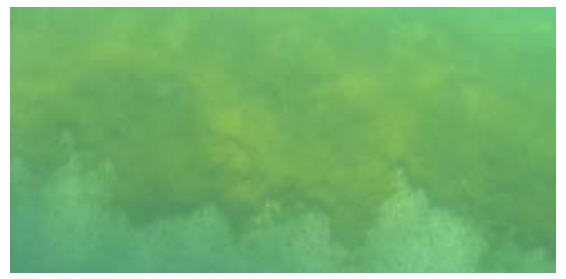

Photo 6: Over $50 \mathrm{~mm}$ of algae on container [1 month after placement]

Jackson, Reichelt, Restall, Corbett, Tomlinson \& McGrath 
Proceedings of the $29^{\text {th }}$ International Conference on Coastal Engineering 19-24 ${ }^{\text {th }}$ September 2004 Lisbon, Portugal

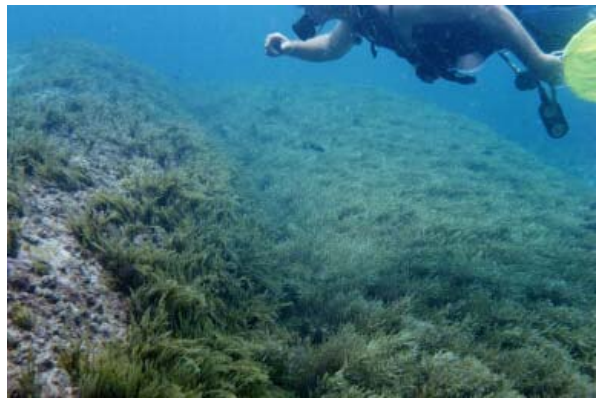

Photo 7: Short algae and seagrasses on shallower containers

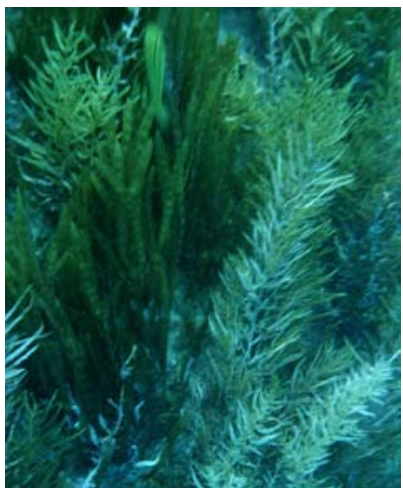

Photo 8: Longer Algae and Seagrasses in mid depths

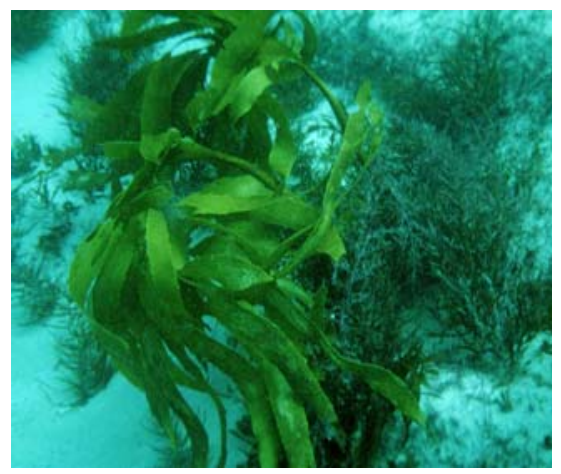

Photo 9: Kelp in deeper containers

Jackson, Reichelt, Restall, Corbett, Tomlinson \& McGrath 


\subsection{Benthos}

With the ecosystem on the reef now well developed, a clear zonation between areas of seagrasses and kelps can be observed. Visually, the macroalgal communities dominate the reef, covering over $70 \%$ of the reef surface. It is, however, also populated by a variety of other benthos, including coralline algae, sub-massive sponges, ascidians [Photo 10], octocorals (soft corals) [Photo 11], hydroids and crinoids (feather starfish) [Photo 12], echinoids (sea urchin) and abalone (Haliotis sp) [Photo 13]. A full list of observed species can be found in the Appendix.

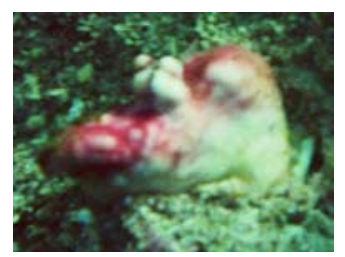

Photo 10: Ascidian

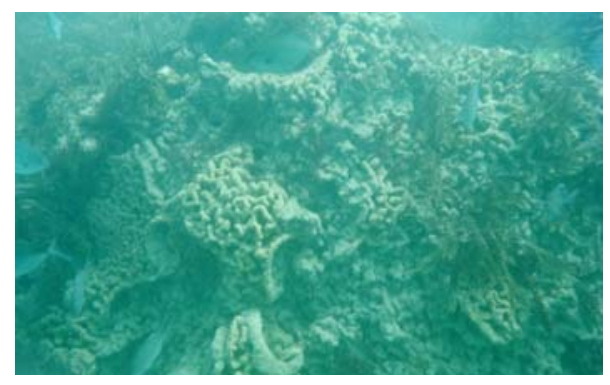

Photo 11: Soft Corals

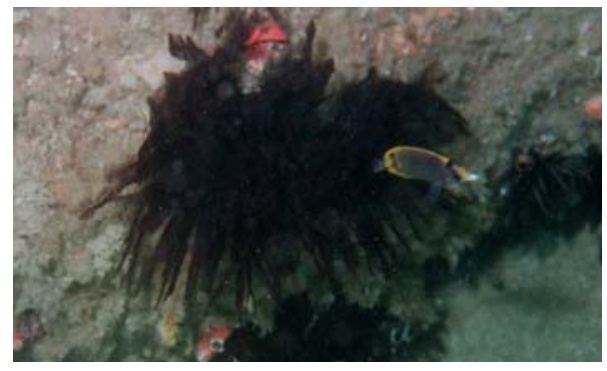

Photo 12: Feather Starfish

Jackson, Reichelt, Restall, Corbett, Tomlinson \& McGrath 

19-24 $4^{\text {th }}$ September 2004 Lisbon, Portugal

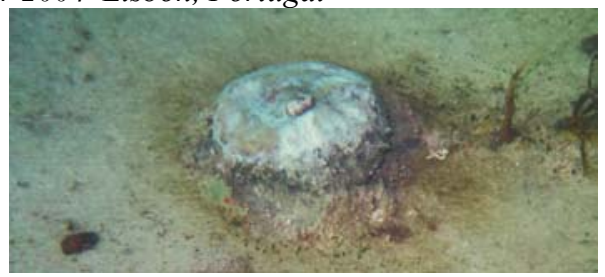

Photo 13: Abalone

Edwards (2003b) noted that the dominance of macroalgae and the lack of hard corals observed at Narrowneck were similar to observations of Kirra Reef, a natural reef south of Narrowneck which has been completely smothered by sand during recent years. This indicates that the algal-dominated community 'may represent an early 'pioneer' development phase. Given sufficient time and suitable conditions for development, the structure of this community might be expected to become more diverse as other benthic organisms begin to outcompete these large macrophytes."

\subsection{Nekton}

The artificial reef has a fish attracting effect, with an abundance of fish such as plankton feeding schools of bait fish, particularly Yellow-tail Mackerel Scad (Trachurus novaezelandiae) [Photo 14] as well as larger migrants such as Snapper (Acanthopagrus auratus) and Tailor (Pomatomus saltrix). Other marine fauna found at Narrowneck include turtles (Chelonia mydas and Caretta caretta) [Photo 15], crayfish (Jasus and Panulirus spp), juvenile shrimp, seahorse, a number of shark species [Photo 16] and stingray. In addition, the reef is close to the migration path for Humpback Whales at certain times of the year. A full list of observed species can be found in the Appendix.

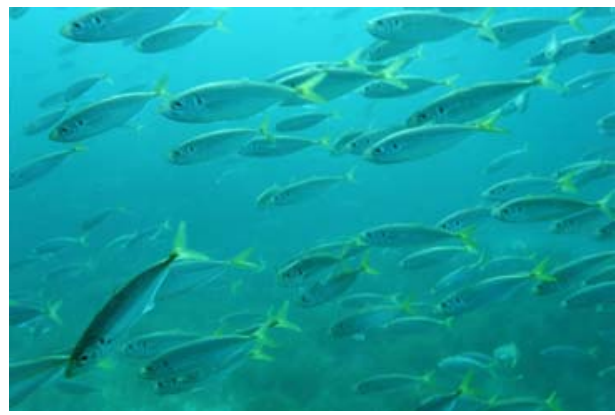

Photo 14: Yellow-tailed Scad

Jackson, Reichelt, Restall, Corbett, Tomlinson \& McGrath 


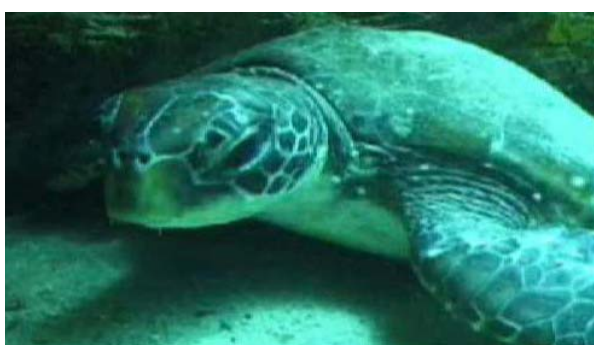

Photo 15: Green Turtle

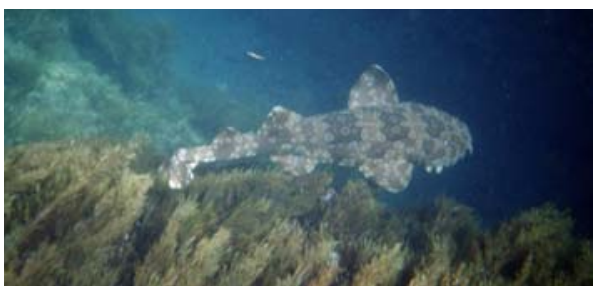

Photo 16: Wobbegong

Transects undertaken by NMSC on the Narrowneck Reef and three natural reefs indicate that four species were found only at Narrowneck, these being the spotted Wobbegong (Orectolobus maculates), Fortescue (Centropogon australis), Brown Dottyback (Pseudochromis fuscus) and Moses Perch (Lutjanus russelli) (Edwards 2003b).

It also revealed that the Narrowneck Artificial Reef has a higher abundance of pelagic fish than similar natural reefs in the area and comparable species diversity. Analysis showed a "high degree of similarity" between the Narrowneck Reef and two of the natural reefs observed.

A relatively lower species diversity and abundance of demersal and benthic fish was observed in comparison to nearby natural reefs. This may be attributable to the relative age of the reef (given that benthic and demersal reef fish communities tend to develop over time); the fact that the survey was undertaken in $10 \mathrm{~m}$ of water, on the outskirts of the reef where the structure is less complex; or the nature of the reef itself.

\title{
2.4. Overall Diversity
}

The Narrowneck Artificial Reef provides a "novel habitat suitable for colonization by many species of benthos, whilst the configuration of reef modules provides a range of habitats that serve as shelter for more mobile

\author{
Jackson, Reichelt, Restall, Corbett, Tomlinson \& McGrath
}


Proceedings of the $29^{\text {th }}$ International Conference on Coastal Engineering 19-24 $4^{\text {th }}$ September 2004 Lisbon, Portugal

organisms." (Edwards 2004b) The Narrowneck Artificial Reef has increased the local diversity, providing a habitat suitable for occupation by many marine creatures that would otherwise be unlikely to persist in the dynamic sanddominated environment that existed prior to construction.

Except for the similarities in terms of pelagic fish populations, Narrowneck is typically dissimilar to other natural reefs in terms of benthos and benthic / demersal fish populations. It should also be considered that there was a high variability between natural reefs observed and the within-reef variability of both the Narrowneck Reef and natural reefs was also high.

The diverse ecological community on the reef reflects the influence from the East Australia Current, which brings larvae from the Great Barrier Reef, and the South East Trade Winds that cause periodic reversal of flows bring subtropical-temperate species from further south. This is consistent with observations by Edwards (2003b) that Narrowneck is "unrepresentative of natural reefs in the region and was probably more similar to the temperate reef assemblages typical of higher latitudes."

Considering the fact that it is only five years since construction of the Narrowneck Reef and the observations of ecosystem development over this time, it is likely that the Narrowneck Reef will continue to evolve and biodiversity of benthos and demersal fish will increase.

\section{Production vs Attraction}

It is often argued that artificial reefs merely serve to redistribute existing resources from natural sites to artificial sites and do not actually increase fish production. It is true that Narrowneck acts, at least in part, as a fish attraction device. This was clear when higher levels of pelagic fish were observed very quickly after placement of the initial containers. However, the presence of juvenile prawns, resident (benthic and demersal) fish and species not observed on nearby natural reefs, as well as the fact that species communities are substantially different to other natural reefs in the region, seems to indicate that the fish at Narrowneck are not only relocated from nearby reefs.

Observations by the National Marine Science Centre indicate that "the biological communities associated with Narrowneck Artificial Reef appear to enhance biodiversity and productivity at a local scale and may also contribute to overall regional productivity." (Edwards 2003a)

\section{Conclusion}

The Narrowneck Reef experience clearly demonstrates the potential for these types of structures both to enhance the ecological environment and

Jackson, Reichelt, Restall, Corbett, Tomlinson \& McGrath 
improve recreational amenity (McGrath 1999). Given the potential value for an eco-tourism experience, the creation of small 'hotspots' of biodiversity raises the issue of local protection for the area from damage by anchors or fishing. There is potential for the reefs to become marine-managed areas, designed to achieve results not only for beach protection and surfing, but also dive-based tourism including photography and self-guided underwater trails.

\section{Appendix}

\section{BENTHOS}

Abalone (Haliotis sp).

Anenome, Sea (Anthozoa)

Ascidian (Family: Ascidiidae)

Barnacles (Cirripedia)

Clam, Razor (Siliqua pathula)

Corals, soft (Octocorallia)

Cunjevoi (Pyura stolonifera)

Feather star fish (Comanthina schlegeli)

Hydroids

Kelp, broad leaf

Kelp, narrow leaf

Polychaete, Tube-building (Family : Diopatra)

Seaweed / Algae, Brown (Dictyopteris acrostichoides)

Seaweed / Algae, Brown (Family : Ecklonia)

Seaweed / Algae, Brown (Sargussum biserrula)

Seaweed / Algae, Red (Family : Coralline algae)

Seaweed / Algae, Red (Gracilaria blodgetti)

Sponges, sub-massive

Urchin, Sea (Class: Echinoidea)

\section{NEKTON [FISH]}

Batfish, Tall-fin (Platax teira)

Batfish, Humped (Platax batavianus)

Batfish, Silver (Monodactylus argentius)

Blenny sp. (Family : Blennidae)

Boxfish, Eastern Smooth (Anoplocapros inermis)

Jackson, Reichelt, Restall, Corbett, Tomlinson \& McGrath 
Proceedings of the $29^{\text {th }}$ International Conference on Coastal Engineering 19-24 ${ }^{\text {th }}$ September 2004 Lisbon, Portugal

\section{NEKTON [FISH]}

Bream, Butter (Monodactylus argenteus)

Bream, Silver (Acanthopagrus australis)

Cardinal fish, Five-line (Cheilodipterus quinquelineatus)

Catfish, Estuary (Cnidoglanis macroephalus)

Cod (small groper) (Epinephelus sp.)

Coris, Pink-lined (Coris dorsomaculata)

Dottyback, Brown (Pseudochromis fuscus)

Flathead (Platycephalus fuscus)

Fortesque (Centropogon australis)

Goatfish, Blackspot (Parupeneus signatus)

Hawkfish, Blotched (Cirrhitichthys aprinus)

Kelpfish (Chironemus marmoratus)

Leatherjacket, Large-scale (Cantheschenia grandisquamis)

Mado (Atypichthys strigatus)

Morwong, Red (Cheilodactylus fuscus)

Parma, Girdled (Parma unifasciata)

Parrotfish (Family : Scaridae)

Perch, Moses (Lutjanus russelli)

Pike, Striped Sea (Sphyraena obtusata)

Pineapple fish (Cleidopus gloriamaris)

Puffer fish (Arothron hispidus)

Slender Suckerfish (Echeneis naucrates)

Stripey (Microcanthis strigatus)

Sweep, Silver (Scorpis lineolata)

Sweetlip, Gold-Spotted (Plectorhinchus flavomaculatus)

Tailor (Pomatomus saltrix)

Tang

Toadfish, Stars and Stripes (Arothron hispidus)

Trevally, Golden (Gnathanodon speciosus)

Triggerfish (Family: Balistoidae)

Trumpet fish (Aulostomus chinensis)

Whiting (Family: Sillaginidae)

Wrasse sp. (Family : Labridae)

Wrasse, Blue-streak Cleaner (Labroides dimidiatus)

Wrasse, Crimson-Banded (Notolabrus gymnogenis)

Jackson, Reichelt, Restall, Corbett, Tomlinson \& McGrath 
NEKTON [FISH]

Wrasse, Gunther's (Pseudolabrus guentheri)

Yellowtail Scad, Southern (Trachurus novaezelandiae)

\section{NEKTON - OTHER THAN FISH}

Crab, red spot

Dolphin, Bottlenose (Tursiops truncatus)

Eel, Giant Moray (Gymnothorax javanicus)

Lobster, Southern Rock (Jasus edwardsii)

Lobster, Tropical Rock (Panulirus ornatus)

Octopus sp.

Prawns, Juvenile (Family: Pandalidae)

Ray, Bull (Dasyatis thetidis)

Ray, Common Sting (Trygonoptera testacea)

Ray, Spotted Eagle (Myliobatis australis)

Seahorse (Family: Syngnathidae)

Seasnake

Shark, Blind (Brachaelurus waddi)

Shark, Leopard (Stegostoma fasciatum)

Shark, Shovelnose (Rhinobatus typos)

Shrimp, Coral-banded

Shrimp sp.

Turtle, Green (Chelonia mydas)

Turtle, Loggerhead (Caretta caretta)

Wobbegong, spotted (Orectolobus maculatus)

Jackson, Reichelt, Restall, Corbett, Tomlinson \& McGrath 
Proceedings of the $29^{\text {th }}$ International Conference on Coastal Engineering 19-24 $4^{\text {th }}$ September 2004 Lisbon, Portugal

\section{References}

Edwards, R. 2003a. A Brief Description of the Biological Assemblages Associated with Narrowneck Artificial Reef and Non-Woven Geotextile Substratum. prepared for Soil Filters Australia.

Edwards, R. 2003b. An Investigation into the Biodiversity of a Geotextile Artificial Reef, Narrowneck, Gold Coast, Qld. University of New England Honours Thesis [under the supervision of the National Marine Science Centre]

Jackson, L.A., Tomlinson, R. McGrath, J. and Turner, I. 2002. Monitoring of a Multi-Functional Submerged Geotextile Reef Breakwater. $28^{\text {th }}$ International Conference on Coastal Engineering.

McGrath, J. Boak, L. and Jackson, L.A. 1999. Infrastructure to Enhance the Natural Capacity of the Environment to Support a Tourist Economy - A Coastal Case Study: The Northern Gold Coast Beach Protection Strategy. $14^{\text {th }}$ Australasian Coastal and Ocean Engineering Conference.

Jackson, Reichelt, Restall, Corbett, Tomlinson \& McGrath 